\title{
Amount of stimulus exploration and preference as differential functions of stimulus complexity
}

\author{
JOACHIM F. WOHLWILL \\ CLARK UNIVERSITY
}

\begin{abstract}
Two sets of photographic slides, one made up of scenes from the geographic environment, the other of works of nonrepresentational modern art, were scaled for complexity by obtaining judges' ratings of amount of variation present on several specified stimulus attributes. Fourteen slides defining a sevenpoint scale of complexity were selected from each set and given to college students to obtain measures of (a) amount of exploratory behavior (number of times $S$ chose to expose each slide briefly), and (b) preference (evaluative ratings on a seven-point scale). In accordance with prediction, the former measure emerged as a linearly increasing function of complexity, while the relationship between complexity and preference was curvilinear, reaching $a$ maximum at an intermediate level of complexity. The results are related to Berlyne's distinction between specific and diversive stimulus exploration, and implications for the study of aesthetics are discussed.
\end{abstract}

The variable of stimulus complexity has come in for a good deal of attention in recent research and theorizing on the arousal of behavior (Berlyne, 1960; Dember \& Earl, 1957; Munsinger \& Kessen, 1964; Vitz, 1966a, b; Walker, 1964). Central to much of this work is the concept of an optimal level of stimulation (Fiske \& Maddi, 1961; Leuba, 1955) according to which positive affect is produced by stimuli representing a certain value on the scale of complexity, determined by the individual's normal level of stimulation, or more particularly, by some deviation from this adaptation level (e.g., Terwilliger, 1963).

This concept of an optimal level of stimulation clearly dictates a research design embodying systematic variation of stimuli along the continuum of complexity. This feature is conspicuously absent in the earlier work of Berlyne investigating the effects of complexity, as in that of others (e.g., Smock \& Holt, 1962) directly inspired by Berlyne's, in which stimuli were typically dichotomized into high vs low complexity, or at best into trichotomous categories. More recently, however, a number of researchers (Munsinger \& Kessen, 1964; Vitz, 1966a, b) have constructed sets of stimuli varying over an extended range of the complexity dimension, and scaled on an a priori basis, by defining this variable in information-theory terms and constructing randomly generated stimuli of specifiable amounts of information content. Utilizing both auditory and visual patterns, Vitz has indeed confirmed that the most preferred stimuli occupy an intermediary position on the scale of complexity. This optimum varies considerably from one individual to another (these individual differences being related to musical training, in the case of the auditory patterns); it is also subject to shifts as a function of repeated exposure to the stimulus materials. The results of the work of Munsinger and Kessen (1964) are generally in agreement with Vitz's.

It should be noted, however, that in both Vitz's and Munsinger and Kessen's research, the dependent variable consisted of ratings of pleasantness, or similar measures of preference, liking, etc. This contrasts with the measures utilized by Berlyne and others, who have been concerned with the role of stimulus complexity in the arousal of behavior and in investigatory or exploratory behavior, and who have accordingly relied on such measures as amount of fixation time, number of voluntary exposures of a stimulus, etc. This work has generally shown a greater amount of exploratory behavior elicited by the most complex stimuli, but since stimulus complexity has in this work been varied only in dichotomous or trichotomous terms, the question whether a similar optimizing function as that found with the preference measure applies to these measures of exploratory activity remains to be answered.

That the functions relating these two types of measures to complexity will differ is suggested by the results of a study by Berlyne (1963), in which it was found that, while high-complexity stimuli elicit a greater amount of looking-behavior than low-complexity stimuli, if $S$ is pre-exposed to both stimuli for at least several seconds, and is then given a choice of one or the other to look at again, he tends rather to prefer the low-complexity one. Berlyne further found that "interestingness" ratings are positively related to complexity, while "pleasingness" ratings are negatively related to the same stimulus variable. On the basis of this and other related findings, Berlyne suggests a differentiation between two kinds of exploratory behavior: one, specific exploration, is primarily aimed at securing information for the individual, while the other, diversive exploration, has an affective, emotion-arousing basis. The former would be implicated in measures of amount of exploratory activity, or interestingness ratings, while the latter $\therefore$ ould be involved in preferential-choice measures, or ratings of pleasingness, liking, etc.

In the light of this analysis, the optimization function found for preference ratings should be expected to be either altogether absent for measures of exploratory behavior, or at least considerably shifted towards the high-complexity part of the scale. Presumably, investigatory activity should increase monotonically as complexity increases, i.e., as the stimulus presents increasing amounts of information to be assimilated by the individual, within limits only of fatigue, mental "dazzle," or the like. Accordingly, the major purpose of the present investigation was to compare the shape of the functions relating stimulus complexity to (a) amount of voluntary exploratory activity, and (b) affective ratings. The hypothesis was that stimulus complexity would be found to be a monotonically increasing function of complexity for the former measure, and an inverted- $U$ shaped function for the latter.

A secondary aim of this investigation was to determine whether results obtained heretofore with artificially constructed stimuli such as nonsense shapes and random series of tones could be generalized to less artificial stimuli. Two such domains of stimuli were selected for study. One represents the world of the physical or geographic environment to which the individual is exposed during the course of his everyday life, his travels, etc. The other represents the world of art, and more particularly of 20th-century non-representational art. Interest in the first domain was prompted by the increasing concern with the quality of the world of stimulation represented by our physical environment, and the conviction that these problems are analyzable in terms of theories of arousal, curiosity and exploratory behavior such as Berlyne's and Fiske and Maddi's (cf. Wohlwill, 1966). Interest in the second domain derived from the apparent relevance of the concepts and findings in the field of curiosity and exploratory behavior to problems of aesthetics (cf. Berlyne, 1960, Chap. 9; Platt, 1961). By working with two very different types of non-artificial stimuli, furthermore, a more adequate picture of the generalizability of the findings based on artificial, controlled stimuli would be obtained.

The use of such stimuli admittedly creates some difficult problems of scaling. Our approach was based on the conception of Fiske and Maddi (1961) and others, who identify complexity with amount of variation present in the stimulus. Accordingly the scaling of the stimuli to be used was achieved by asking judges to rate them for amount of variation along each of several specified stimulus dimensions. This approach, utilizing human observers 
Table 1

Description of Phyeced Eavironment Slides Utilized to Repreaent Different Levels of Judged Complexity

\begin{tabular}{|c|c|c|c|c|c|}
\hline \multirow[b]{2}{*}{$\begin{array}{l}\text { Complexity } \\
\text { Level }\end{array}$} & \multirow[b]{2}{*}{ Description of Slide } & \multicolumn{2}{|c|}{ Complexity Ratings" } & \multirow{2}{*}{$\begin{array}{c}\text { Number of } \\
\text { Expowures } \\
\text { (Means) }\end{array}$} & \multirow{2}{*}{$\begin{array}{c}\text { Preference } \\
\text { Ratings } \\
\text { (Means) } \\
\end{array}$} \\
\hline & & Mean & Range & & \\
\hline 1 & Ros Ice Shelf & 5.0 & a & 4.82 & 3.50 \\
\hline 1 & Sky and Ice, Antarctica & 5.2 & 1 & 5.32 & 3.54 \\
\hline 2 & $\begin{array}{l}\text { Ice Pack with Overcest Sky } \\
\text { and Field }\end{array}$ & 6.8 & 5 & 5.18 & 4.39 \\
\hline 2 & Rough Sea, Sky & 7.0 & 5 & 4.61 & 3.93 \\
\hline 3 & Farmatead, Great Plains & 9.2 & 3 & 5.32 & 3.69 \\
\hline 3 & Grasty Field, Wisconsin & 10.2 & 3 & 6.18 & 4.53 \\
\hline 4 & $\begin{array}{l}\text { Lake scene with partial view } \\
\text { of thore }\end{array}$ & 12.0 & 2 & 7.71 & 6.00 \\
\hline 4 & Key Bridge over the Potomac & 12.0 & 5 & 5.47 & 3.93 \\
\hline 5 & Farmatead with plowed field & 14.4 & 6 & 5.14 & 4.00 \\
\hline 5 & $\begin{array}{l}\text { Factory and downtown area } \\
\text { of amall city }\end{array}$ & 15.0 & 5 & 4.89 & 2.32 \\
\hline 6 & Baltimore Waterfront & 17.8 & 2 & 5.47 & 4.36 \\
\hline 6 & $\begin{array}{l}\text { Chicago Skyline across mouth } \\
\text { of Chicago River }\end{array}$ & 18.6 & 5 & 8.93 & 4.82 \\
\hline 7 & $\begin{array}{l}\text { Center of Madison, Wisc., } \\
\text { (view from Capitol) }\end{array}$ & 19.8 & 6 & 7.39 & 3.61 \\
\hline 7 & Village and Rolling Hills & 20.6 & 8 & 7.89 & 4.43 \\
\hline
\end{tabular}

'Means and ranges tabled are for five judges' total natings, summed over five stimulus attributes. Effective range of totals is from 5 to 25 . (See text.)

essentially as variation-detectors, was calculated to yield judgments of a lesser order of subjectivity than could be expected from direct ratings of phenomenal complexity.

\section{Complexity Scaling}

\section{METHOD}

For the stimuli representing scenes from the physical environment a preliminary selection was made from among a large collection of color slides utilized for instruction in geography, and representing a large variety of geographic loci. The selection was aimed at covering a wide range of the complexity continuum, as well as a diversity of scenes from the physical environment, both natural and man-made. A set of 48 slides was thus obtained, which was randomly divided into two halves. Each half was shown to a different team of five judges-mostly graduate students in psychology-with instructions to rate the pictures to be shown for amount of variation along five attributes: color, shape, direction of dominant lines, texture and natural vs artificial. (With respect to the last-mentioned attribute, scenes that were wholly natural, such as mountain scenery, or wholly man-made, such as a city square, would be given a rating of 1 , while scenes containing a large mixture of the two, e.g., a country road with farm houses, etc., would be given a rating of 5.) Each team of judges had six successive runs through their set of 24 slides; the first was for familiarization purposes, and the succeeding ones for the ratings of the five attributes, in the order indicated above. The slides were projected on a screen by means of a Revere projector, forming approximately an $84 \times 56 \mathrm{~cm}$ image.

The procedure for the complexity-scaling of the art slides was similar. Fourteen slides of modern non-representational paintings were preselected; half of these were shown to each of the two above-mentioned teams of judges. The art slides were always presented following the completion of the ratings for the physical environment slides. Ratings were obtained for four of the five

Table 2

Description of Non-representational Art Slides Utilized to Represent Different Levels of Judged Complexity

\begin{tabular}{|c|c|c|c|c|c|}
\hline \multirow[b]{2}{*}{$\begin{array}{l}\text { Complexity } \\
\text { Level }\end{array}$} & \multirow[b]{2}{*}{ Description of Slide } & \multicolumn{2}{|c|}{ Complexity Ratings } & \multirow{2}{*}{$\begin{array}{c}\text { Number of } \\
\text { Expowres } \\
\text { (Means) }\end{array}$} & \multirow{2}{*}{$\begin{array}{c}\text { Preference } \\
\text { Ratings } \\
\text { (Means) } \\
\end{array}$} \\
\hline & & Mean & Range & & \\
\hline 1 & $\begin{array}{l}\text { Mondrian: Composition in red, } \\
\text { yellow and blue }\end{array}$ & 6.5 & 4 & 2.96 & 2.93 \\
\hline $\begin{array}{l}1 \\
21\end{array}$ & $\begin{array}{l}\text { Malevich: Suprematist } \\
\text { Malevich: Football }\end{array}$ & $\begin{array}{l}7.0 \\
8.6\end{array}$ & $\begin{array}{l}5 \\
3\end{array}$ & $\begin{array}{l}2.89 \\
4.50\end{array}$ & $\begin{array}{l}2.36 \\
3.57\end{array}$ \\
\hline 2 & $\begin{array}{l}\text { Klee: Brown rectangular } \\
\text { gravitating triangle }\end{array}$ & 9.0 & 5 & 5.79 & 3.79 \\
\hline 3 & Mondrian: Composition, 1916 & 10.2 & 1 & 3.50 & 3.00 \\
\hline 3 & Klee; Earth Spirits & 10.6 & 4 & 4.97 & 4.39 \\
\hline 4 & Kandinsky: Two circles & 12.0 & 6 & 5.96 & 4.50 \\
\hline 4 & Klee: Ludus Martis & 12.2 & 6 & 5.43 & 3.61 \\
\hline 4 & Picasso: The table & 12.4 & 6 & 5.93 & 4.11 \\
\hline 5 & Leger: The bird charmer & 14.6 & 3 & 6.39 & 3.97 \\
\hline 5 & Miro: Painting, 1953 & 14.8 & 4 & 6.50 & 4.36 \\
\hline 6 & Pollock: Convergence & 16.4 & 5 & 6.00 & 4.07 \\
\hline 6 & Kandineky: 183 & 17.2 & 3 & 7.57 & 4.54 \\
\hline 7 & Leger: New York & 18.2 & 4 & 8.25 & 3.93 \\
\hline
\end{tabular}

bMeans and ranges tables are for five judges' total ratings, summed over four stimulus attributes. Effective nange of totals is from 5 to 20 . (See text.) 
attributes used for the latter, omitting the natural-artificial variation scale.

The final selection of the slides to be utilized for the main part of the experiment proceeded as follows. For the environment slides, 14 were chosen from the total set of 48 , so as to provide, as nearly as possible, a set of seven approximately equally spaced points on the complexity continuum (as indexed by the composite ratings obtained by summing across the five attributes, averaged over the five judges). Where a choice among possible alternatives was possible, the extent of interjudge agreement (the range of the totals for the five judges), as well as agreement with the results of a prior pilot study in which some of the same slides had been used was taken into account. For the art slides, all 14 of the slides for which complexity ratings had been obtained were selected for the study. They likewise could be ordered along a seven-step complexity scale, with two slides at each step, except that the middle point of the scale was defined by three slides and the upper extreme by only one.

A brief description of both sets of slides, together with their mean complexity ratings is given in Tables 1 and $2 .^{3}$ (The last two columns of these tables present the results obtained for each slide-cf. Results section.)

An indication of the stability of these scaled complexity values is afforded by the results obtained from a further group of five judges, for whom the order of the ratings of the various stimulus dimensions was counterbalanced. This new set of means showed a rank-order correlation with the original values of .97 for the art slides, and .96 for the environment slides.

\section{Procedure for Obtaining NE and R Measures}

The experiment started with the number-of-exposures (NE) phase for the first set of slides. $E$ asked $S$ to sit down on a chair about $10 \mathrm{ft}$ from the screen, and gave him the following instructions: "This is a study of people's interest in pictures-all kinds of pictures. You will see some slides of paintings and scenes from the world around us, both natural and man-made. Each picture will appear for only a brief moment, but you can look at any picture as often as you like. I will flash each picture repeatedly, until you tell me to go on to the next. Please be assured that there is no ulterior purpose to this experiment-we will not ask you what or how much of what you saw, you noticed, or can remember later, or anything like that. We simply want to determine your own interest in what you see."

The $E$ then went through one complete run of the first set of slides, exposing each repeatedly for $.5 \mathrm{sec}$ at a time (by releasing the shutter of a tachistoscope attached to the projector), until $S$ said "next." (Interval between successive exposures was approximately $1 \mathrm{sec}$.) The entire set of slides was then shown again under unlimited exposure for the ratings (R) phase, with instructions to $S$ to call out a number between 1 and 7 to indicate how well he liked the picture he was looking at. The identical procedure was then repeated for the second set of slides. Projection conditions duplicated those used for the judges' ratings.

Half of the Ss started with the environment slides, the other half with the art slides. Within each of these halves, an equal number of Ss saw the slides in a forwards and a backwards order. Each of these four subgroups was composed of seven Ss; each S

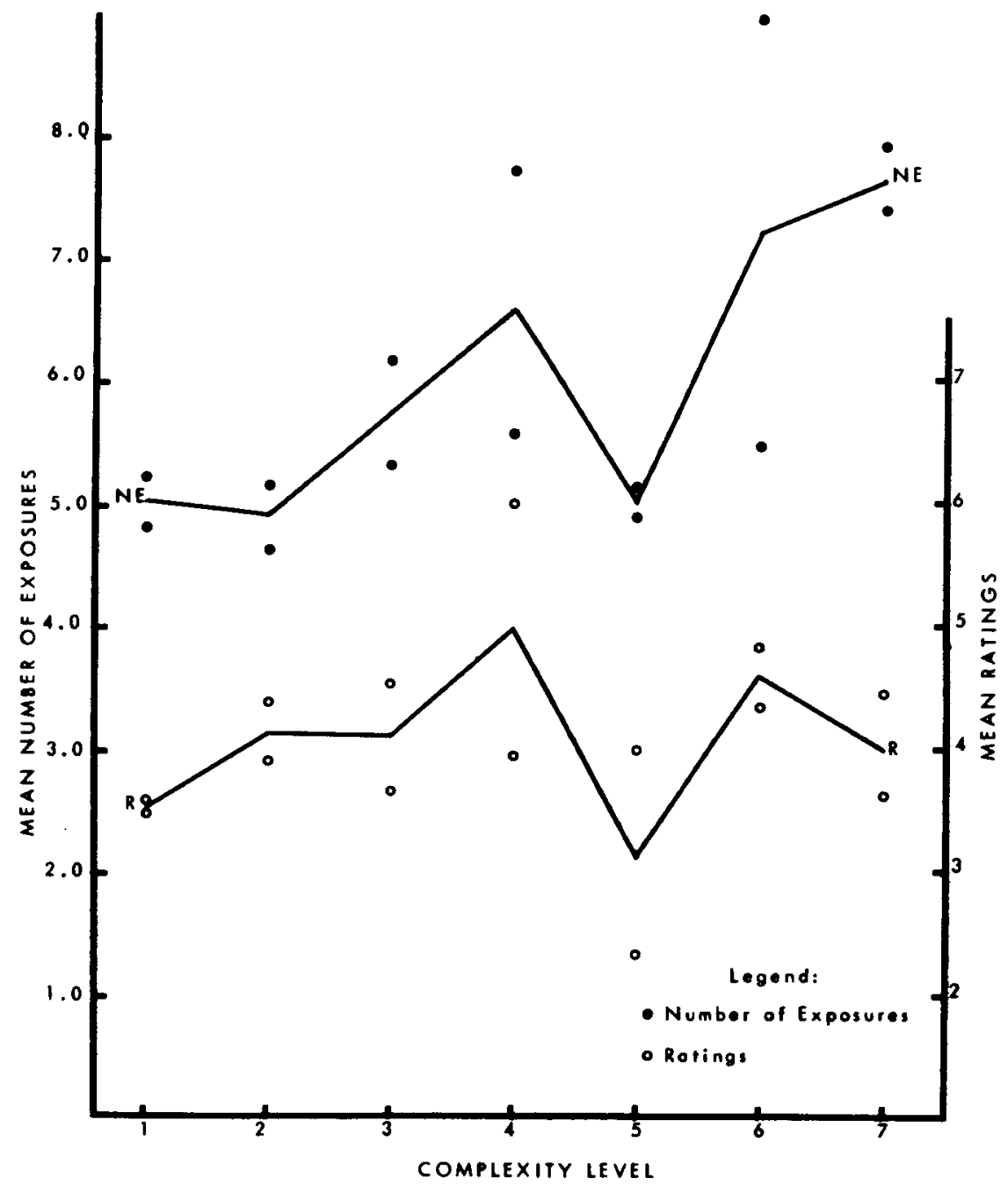

Fi- 1. Menn number of exposures (NE) and preference rating (R) for slides of physical eavionment exies. (Line graphs represent average values for dides at each level of complexity.) 
within a subgroup started at a different point in the sequence of 14 slides comprising each set.

\section{Questionnaire}

At the conclusion of the experimental session, Ss were given a brief questionnaire, to provide information as to the type of environment (urban, suburban, or rural) in which they had been residing, their preferred geographic area for their future residence, their preferred leisure activities (outdoors vs indoors), their acquaintance with both pre-modern and modern painters, and an expression of their liking for modern art.

\section{Subjects}

The Ss were 28 students enrolled in undergraduate summer school courses; there were 13 males and 15 females, ranging in age from 16 to 23 (Mean $=20.1$ years).

\section{RESULTS}

Figure 1 shows the mean ratings ( $R$ ) and mean number of exposures (NE) for the seven pairs of environment slides arranged in order of judged complexity. Figure 2 presents the same data for the art slides. (The numerical values of the means of each slide are given in Tables 1 and 2.)

It will be noted that both sets of curves follow a similar pattern. For both the environment slides and the art slides, though more consistently so in the case of the latter, the trend is for the NE data to increase monotonically as a function of stimulus complexity, while the $\mathbf{R}$ data follow a curvilinear trend, reaching a maximum at an intermediate point of the complexity scale. The major departure from these general patterns is the dip in both the $\mathrm{NE}$ and $\mathrm{R}$ measures at Level 5 of the complexity scale for the environment slides. The basis for these aberrant values is difficult to fathom, especially since both slides at that level contributed to them about equally, even though they were quite dissimilar in content (one being a rather unattractive view of a downtown area of a small city, featuring an ancient-looking factory, the other being a fairly pleasing parcel of cultivated farmland with a farmstead in the background).

The differences between the shapes of these two functions receive confirmation from trend analyses carried out on these data (Table 3). For the purposes of this analysis, the values for each $S$ for the pair of slides at each level of complexity were averaged. For the NE measure only the linear trends were significant. Due to the marked skewness of the NE data, that analysis was replicated on a logarithmic transformation of these data; the result was the same. (It is recognized that the application of trend analysis to these data cannot, strictly speaking, be justified; first, the points on the complexity scale are not separated by exactly equal intervals and, second, the metric underlying the original complexity judgments is uncertain. But the difference between the monotonically increasing and inverted- $U$ shaped trends established by the analysis does not in fact depend on the equal-interval assumption, since it would be maintained under any scale transformation that preserved the ordinal relationships among the points.)

The analyses summarized in Table 3 further indicate that on both measures the linear trend is steeper for the art slides than for the environment slides (significant linear component for the

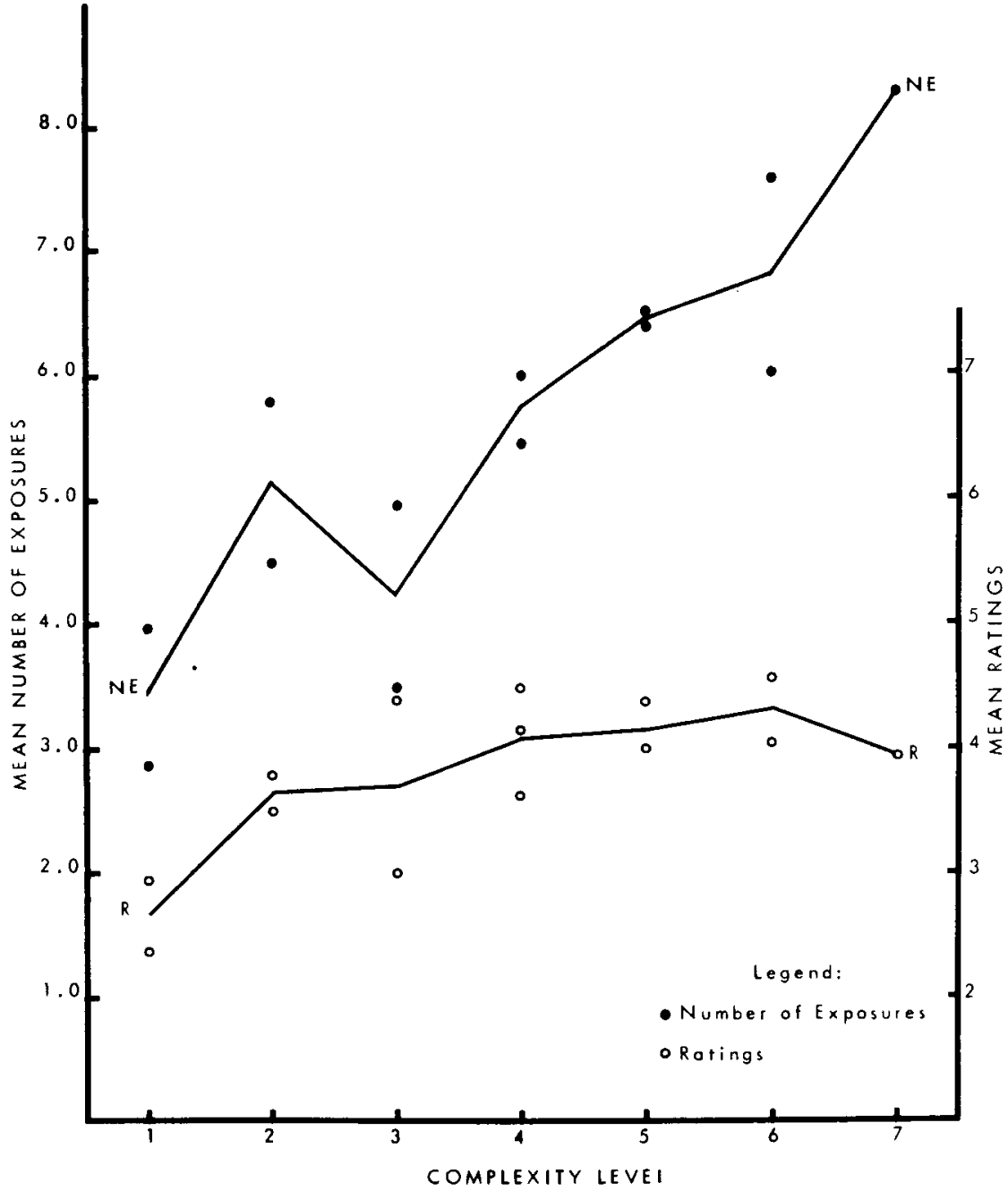

Fig. 2. Mean number of exposures (NE) and preference ratings (R) for slides of non-representational modern art series. (Line graphs represent average values for slides at each level of complexity.) 
Table 3

Summary of Trend Analyses on NE and R Data

\begin{tabular}{|c|c|c|c|c|c|c|c|}
\hline \multirow[b]{2}{*}{ Source of Variance } & \multirow[b]{2}{*}{ df } & \multicolumn{3}{|c|}{ NE Data } & \multicolumn{3}{|c|}{ R Data } \\
\hline & & S. SQ. & M.SQ. & $\mathbf{F}$ & S. SQ. & M. SQ. & $\mathbf{F}$ \\
\hline Total & 391 & 8627.03 & & & 883.81 & & \\
\hline Between Ss & 27 & 4618.58 & & & 207.87 & & \\
\hline Within Ss & 364 & 4008.45 & & & 675.94 & & \\
\hline Sets (Env. vs Art) & 1 & 8.84 & 8.84 & 0.53 & 8.58 & 8.58 & $6.53^{*}$ \\
\hline Ss x Sets & 27 & 451.43 & 16.72 & & 35.52 & 1.32 & \\
\hline Complexity Levels & 6 & 549.22 & & & 78.89 & & \\
\hline Linear Trend & 1 & 497.81 & 497.81 & $41.35 * *$ & 24.13 & 24.13 & $13.12 * *$ \\
\hline Quadratic & 1 & 11.13 & 11.13 & 0.92 & 20.49 & 20.49 & $11.15^{* *}$ \\
\hline Cubic & 1 & 9.00 & 9.00 & 0.74 & 3.64 & 3.64 & 1.98 \\
\hline Residual & 3 & 31.27 & 10.42 & 0.86 & 30.63 & 10.21 & 5.55 \\
\hline Ss $\mathrm{x}$ Levels & 162 & 1950.22 & 12.04 & & 297.80 & 1.84 & \\
\hline Sets $x$ Levels & 6 & 107.48 & & & 34.59 & & \\
\hline Linear Trend & 1 & 35.07 & 35.07 & $6.04^{*}$ & 8.80 & 8.80 & $6.47^{*}$ \\
\hline Quadratic & 1 & 0.45 & 0.45 & 0.08 & 1.41 & 1.41 & 1.04 \\
\hline Cubic & 1 & 0.00 & 0.00 & 0.00 & 1.71 & 1.71 & 1.26 \\
\hline Residual & 3 & 71.96 & 23.99 & 4.14 & 22.66 & 7.55 & 5.55 \\
\hline Ss $\mathrm{x}$ Sets $\mathrm{x}$ Levels & 162 & 941.27 & 5.81 & & 220.55 & 1.36 & \\
\hline
\end{tabular}

${ }^{*} p<.025$

$* * p<.01$

Complexity Levels by Set interaction). A further analysis, comparing the overall means for the two sets of slides, showed higher $R$ values for the environment than for the art slides $\left(\overline{\mathrm{X}}_{\mathrm{E}}=4.08 ; \overline{\mathrm{X}}_{\mathrm{A}}=3.78 ; \mathrm{F}=6.52 ; \mathrm{df}=1 / 27\right)$, but no significant differences on the NE measure $\left(\overline{\mathrm{X}}_{\mathrm{E}}=6.02 ; \overline{\mathrm{X}}_{\mathrm{A}}=5.72 ; \mathrm{F}=0.53\right.$; $\mathrm{df}=1 / 27$ ). It is interesting to note, furthermore, that there were no time-order effects, i.e., on neither measure was there a significant difference between the first-shown and the secondshown set. Finally, examination of the means for the initial, middle and final portions of each series of slides gave no evidence of any consistent sequential effects such as satiation operating within a series.

The equivalence between the two halves of the session is worth noting, in view of the fact that the ratings were always obtained following the NE phase. (It was not possible to counterbalance order, since NE data obtained following an exposure to each slide sufficiently long for $S$ to make his rating would have little validity.) Since there is so little evidence of any systematic change over time in either sets of measures, it appears implausible to attribute the difference in the shape of the two functions to the order-of-presentation factor.

Since every point of the complexity scale was represented by two different slides (with the exception, as will be recalled, of the fourth and seventh points for the art slides), an opportunity presents itself to assess the extent to which the complexity variable did indeed account for the variation among the means for each slide, by means of the correlation ratio. The results of this analy sis show that complexity was more closely related to the NE than to the $R$ measures, and that the art slides showed more consistency in this regard than did the environment slides. While the values of $\mathrm{E}^{2}$ vary between .81 (NE-Art) and .50 (R-Environment), the unbiased correlation ratio $\left(\epsilon^{2}\right)$ was significant only for the NE data obtained from the art slides. This is not surprising, since only two slides were available at each point of the complexity scale to provide an estimate of within-level variance. All in all, considering the diversity in content between the slides assigned identical complexity values, the correspondence in the results for each pair is remarkable.

Finally, several analyses concerning aspects of intersubject variation on our measures are of interest. These analyses are based for the most part on the calculation of linear- and quadratic-trend coefficients for each $\mathrm{S}$, representing the linear and quadratic regression of the $\mathrm{NE}$ and $\mathrm{R}$ measures for each $\mathrm{S}$ on the complexity scale. (These coefficients were obtained by multiplying the mean ralues for NE and $\mathrm{R}$ at each point of the complexity scale by the corresponding orthogonal-polynomial weights, and summing these cross-products.)

These coefficients provide us, first of all, with an indication of intra-individual consistency in response to complexity across different domains. Thus we find a correlation of $.47(p<.01)$ between the linear-trend coefficients for the art and the environment slides for the NE data, and a correlation of .30 ( $p>.05$ ) for the $R$ data. The corresponding figures for the quadratic-trend coefficients are -.27 and .02 (nonsignificant).

On the other hand, the linear-trend coefficients for NE failed to relate significantly to any of a variety of background data available on our Ss. Among the more obvious ones were included: urban vs nonurban residence and preferred leisure-time activities (e.g., outdoor vs indoor) in relation to the environment slides, and acquaintance with modern painters and expressed liking for modern art, such as Picasso's, in relation to the art slides. In this respect the results confirmed Vitz's (1966b) lack of success in relating S's maximum preferred level of complexity of his nonsense figures to training in art, although Munsinger and Kessen (1964), and Vitz (1966a) himself, in his study with auditory patterns, did find the curve for Ss with relevant training to be shifted substantially towards the high-complexity end of the scale, relative to their untrained Ss.

\section{DISCUSSION}

The main hypothesis of the study, that measures of visual exploration and preference ratings would relate differentially to stimulus complexity, was confirmed for both the art and the environment slides. This finding fits in readily with Berlyne's distinction between specific and diversive exploration referred to in the introduction. Presumably, the number of times that an individual voluntarily exposes a stimulus briefly to view reflects the potential interest-value of that stimulus in eliciting investigatory responses; this value would be expected to increase with increasing complexity, since the more variation there is in the stimulus field, the more information there is for the individual to process. If we then assume a model of the individual such as Berlyne's directed at uncertainty reduction (or conflictresolution), a monotonically increasing function relating amount of investigation or exploration to complexity would follow. The preference ratings, on the other hand, follow the same pattern up to a point, beyond which one may presume that further increases in interest deriving from variation are offset by the increasing effort required of the individual to process the information. Thus it is that we find the curvilinear and even inverted- $U$ shaped 
functions relating preference to complexity, as shown both in our study and in the prior work of Munsinger and Kessen and of Vitz cited in the introduction.

One question which arises here is whether amount of visual exploration may not also follow an inverted- $U$ shaped trend, the function being shifted upward relative to that for complexity, but likewise declining if complexity increases beyond a certain point. It is entirely possible that our stimuli simply did not include a sufficiently extreme degree of complexity to reveal such a decreasing phase. That this may indeed represent the true picture is suggested by the results from one of a series of studies most recently reported by Day (1967). This investigator compared judgments of interestingness with judgments of pleasingness as a function of stimulus complexity, utilizing nonsense shapes varying in number of sides. In Day's Study 4, which contained the most extensive sampling of the complexity continuum (with figures varying from 10 to 160 sides), inverted- $U$ shaped functions were found for both sets of judgments, with pleasingness peaking at about 20 sides, while interestingness reached a peak at 28 , and a second subsidiary one at about 48 sides. The generalizability of these findings is uncertain, however, since the trends in the first three of the studies reported by Day are rather more irregular and inconsistent.

Let us note in closing that our results inspire confidence in the generalizability of findings based on artificially constructed visual and auditory patterns to more meaningful or aesthetically relevant ones. The way is thus left open to an experimental approach to basic questions in aesthetics through systematic application of principles established in the laboratory investigation of effects of stimulus complexity, as well as the other "collative" variables discussed by Berlyne (1960).

\section{REFERENCES}

BERLYNE, D. E. Conflict, arousal and curiosity. New York: MoGraw-Hill, 1960.

BERLYNE, D. E. Complexity and incongruity variables as determinants of exploratory choice and evaluative ratings. Canadian Journal of Psychology, $1963,17,274-290$.

DAY, H. Evaluations of subjective complexity, pleasingness and interestingness for a series of random polygons varying in complexity. Perception \& Psychophysics, 1967, 2, 281-286.

DEMBER, W. N., EARL, R. W. Analysis of exploratory, manipulatory and curiosity behavior. Psychological Review, 1957, 64, 91-96.

FISKE, D. W., \& MADDI, S. R. The forms of varied experience. In D. W. Fiske and S. R. Maddi (Eds.), Functions of varied experience. Homewood, III.: Dorsey Press, 1961. Pp. 1-56.

LECKART, B. T., BAKAN, P. Complexity judgments of photographs and looking time. Perceptual and Motor Skills, 1965, 21, 16-18.
LEUBA, C. Toward some integration of learning theories: The concept of optimal stimulation. Psychological Reports, 1955, 1, 27-33.

MUNSINGER, H., \& KESSEN, W. Uncertainty, structure and preference. Psychological Monographs: General and Applied, 1964, 78, No. 9 (Whole No. 586).

SMOCK, C. D., \& HOLT, B. G. Children's reactions to novelty: An experimental study of "curiosity motivation." Child Development, 1962, $33,631-642$.

PLATT, J. R. Beauty: Pattern and change. In D. W. Fiske and S. R. Maddi (Eds.), Functions of varied experience. Homewood, Ill.: Dorsey Press. Pp. 402-430.

TERWILLIGER, R. R. Pattern complexity and affective arousal. Perceptual and Motor Skills, 1963, 17, 387.395.

VITZ, P. C. Affect as a function of stimulus variation. Journal of Experimental Psychology, 1966a, 71, 74-79.

VITZ, P. C. Preference for different amounts of viaual complexity. Behavioral Science, 1966b, 11, 105-114.

WALKER, E. L. Psychological complexity as a basis for a theory of motivation and choice. In D. Levine (Ed.), Nebraske symposium on mottuation Lincoln, Neb.: Univer. Nebraka Prea, 1964. Pp. 47-95.

WOHLWLL, J. F. The physical environment: A problem for a paychology of stimulation. In R. W. Kates and J. F. Wohlwill (Eds.), Man's response to the physical environment. Journal of Social Issues, 1966, 22, 29-38.

\section{NOTES}

1. This investigation was supported by funds from a Bio-Medical Sciences Research Grant (No. PHS 7045-02) from the National Institutes of Health to Clark University. The skillful ascistance of Miss Carol Simon in the conduct of this experiment is gratefully acknowledged. Thanks are also due to Dr. George MoCleary of the Clark University Geography Department, and to the Worcester Art Museum, for making their slide collections available for the selection of the physical environment and modem art slides, respectively, uned in this study.

2. Address: Heinz Werner Institute of Developmental Psychology, Clark University, Worcester, Mass. 01610.

3. It will be noted that mean complexity ratings for the pair of slides assigned to each complexity level were not perfectly matched. The discrepancies range from 0 (Level 4, environment slides) to 1.0 (Level 3, same set). Furthermore, the width of the steps between adjoining levels (as defined by the average of the means for the slides defining each level), varies between 1.4 and 2.5 for the art slides, and between 1.8 and 3.5 for the environment slides. Nevertheless, since the metric underlying the original ratings was itself uncertain, and since the average within-level discrepancies are quite small compared to the average distance between adjacent steps, it was decided for purely practical purposes to treat these slides as representing a seven-step equal-interval scale of complexity, as shown in Tables 1 and 2.

(Accepted for publication July 23, 1968.) 